\title{
CHEMICAL CHANGES OF HEAT TREATED PINE AND EUCALYPT WOOD MONITORED BY FTIR
}

\author{
B. Esteves ${ }^{1 \star}$, A.Velez Marques², I. Domingos1, H. Pereira ${ }^{3}$
}

\begin{abstract}
A hardwood, Eucalyptus globulus Labill., and a softwood Pinus pinaster Aiton., were heat treated at temperatures between 170 and $210^{\circ} \mathrm{C}$ in an oven and in an autoclave. The samples were pre-extracted with dichloromethane, ethanol and water and ground prior to Fourier Transform Infrared (FTIR) spectroscopic analysis.

The heat treatment caused significant changes in the chemical composition and structure of wood, in lignin and polysaccharides. Hemicelluloses were the first to degrade as proved by the initial decrease of the $1730 \mathrm{~cm}^{-1}$ peak due to the breaking of acetyl groups in xylan. Hardwood lignin changed more than softwood lignin, with a shift of maximum absorption from $1505 \mathrm{~cm}^{-1}$ to approximately $1512 \mathrm{~cm}^{-1}$ due to decrease of methoxyl groups, loss of syringyl units or breaking of aliphatic side-chains. The macromolecular structure becomes more condensed and there is a clear increase of non-conjugated $\left(1740 \mathrm{~cm}^{-1}\right)$ in relation to conjugated groups $\left(1650 \mathrm{~cm}^{-1}\right)$. However, the changes induced by the thermal treatment are difficult to monitor by FTIR spectroscopy due to the different chemical reactions occurring simultaneously.
\end{abstract}

Keywords: Eucalyptus globulus, FTIR, Heat treatment, Pinus pinaster

\section{INTRODUCTION}

Heat treatment is one of the processes for modifying the wood with greater commercial success. There are different treatments: the Thermowood ${ }^{\circledR}$ process, originated in Finland, uses steam (Viitanen et al. 1994), the Plato ${ }^{\circledR}$ process, developed in the Netherlands, uses a combination of steam and heated air (Tjeerdsma et al. 1998), the Retiwood ${ }^{\circledR}$ process, of French origin, uses an inert gas (Dirol and Guyonnet 1993), the OHT ${ }^{\circledR}$ from Germany, uses hot oil (Sailer et al. 2000) and the Perdure ${ }^{\circledR}$ process, initially developed in France but later sold to a company from Canada (Kocaefe et al. 2008a) uses steam.

Heat treatments lower the equilibrium moisture content of wood (Jämsa and Viitaniemi 2001, Wang and Cooper 2005, Esteves et al. 2007a, Esteves et al. 2007b, Esteves et al. 2008a), increase its dimensional stability (Viitaniemi et al. 1997, Yildiz 2002, Wang and Cooper 2005, Esteves et al. 2007a, Esteves et al. 2007b), and increase its durability (Dirol and Guyonnet 1993, Kamdem et al. 2002) and its darkness (Mitsui et al. 2001, Bekhta and Niemz 2003, Esteves et al. 2008c). The main disadvantage of these heat processes is the reduction of the wood mechanical strength properties, such as static and dynamic bending strength (Yildiz 2002, Esteves et al. 2007b) and resistance to compression (Unsal and Ayrilmis 2005).

\footnotetext{
Centre of Studies in Education, Technologies and Health, School of Technology of Viseu, Polytechnic Institute of Viseu,

Campus Politécnico Repeses, 3504-510, Viseu, Portugal

${ }^{2}$ Research Centre for Chemical Engineering and Biotechnology (CIEQB), Superior Institute of Engineering of Lisbon, Lisbon, Portugal

${ }^{3}$ Forest Research Centre, School of Agronomy, Technical University of Lisbon, Lisbon, Portugal

^Corresponding author: bruno@demad.estv.ipv.pt

Received: 02. 02. 2012 Accepted: 11.11. 2012
} 
There are chemical changes in the the wood during heating. They start by deacetylation of hemicelluloses followed by depolymerization catalysed by the released acetic acid (Tjeerdsma et al. 1998, Sivonen et al. 2002, Nuopponen et al. 2004). Simultaneously hemicelluloses undergo dehydratation with the decrease of hydroxyl groups (Weiland and Guyonnet 2003). In accordance with Esteves et al. (2008b) hemicelluloses are affected first, followed by cellulose and lignin.

FTIR is widely used in quantitative and qualitative analysis of wood because of its capacity to give information on the presence of functional groups, on composition and on some specific structural features.

The main objective of this paper was to track the chemical changes occurring along the heat treatment (two different treatments, one with hot air and the other with steam) of a hardwood (Eucalyptus globulus) and a softwood (Pinus pinaster) by FTIR.

\section{MATERIAL AND METHODS}

Two of the most important tree species in Portugal were tested: the hardwood Eucalyptus globulus Labill. and the softwood Pinus pinaster Aiton. The pine samples were taken from the sapwood of a 40 year old tree from the Portuguese region of Águeda. For the eucalypt samples only heartwood was used from a tree with approximately $1 \mathrm{~m}$ in diameter, from the same region. The samples were treated in an oven and in an autoclave under several operating conditions.

Cubic samples were prepared, with $40 \mathrm{~mm}$ edge, free from knots, resin canals or other singularities, with faces parallel to radial, tangential and longitudinal directions. The samples were stabilized during three weeks in a room conditioned at $50 \%$ relative humidity and $20^{\circ} \mathrm{C}$. The equilibrium moisture content and the mass of all samples were determined.

\section{Oven heat treatments}

The stabilized samples were treated in a Selecta 125 litre oven without forced convection but with an outlet for gases exhaustion. The trials were conducted in the presence of air during 2, 6, 12 and 24 $\mathrm{h}$, at $170^{\circ} \mathrm{C}$ and $180^{\circ} \mathrm{C}$. The time to reach the treatment temperature was one hour. Four samples were used in each test, making up a total of 32 samples for each species. At the end of the heat treatment all samples remained for one hour in a desiccator and were weighted. The mass loss was determined for each sample in relation to its initial dry mass in accordance with:

$$
\text { Mass loss }(\%)=(\text { dry mass- treated mass }) / \text { dry mass * } 100
$$

where the dry mass is the mass of the specimen without treatment, and the treated mass corresponds to the dry mass of the specimen after heat treatment.

\section{Autoclave heat treatment}

The heat treatment in autoclave was carried out in an industrial prototype (Figure 1), used for the production of expanded cork agglomerates, installed in an industrial plant of the Amorim Group located in Silves, Portugal. 


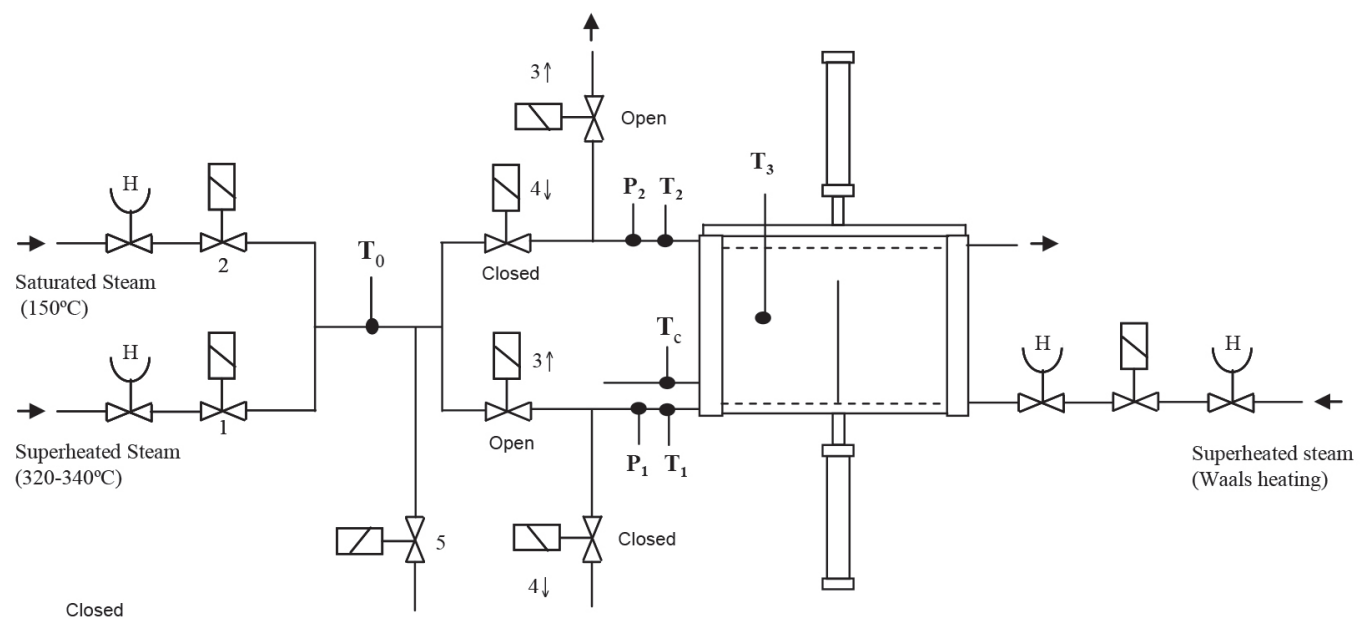

Prototype (AMORIM, Natural Cork Boards Factory, Silves)

Figure 1. Autoclave used in the heat treatment in the absence of oxygen.

The autoclave ( $1 \mathrm{~m}^{2} \times 0.5 \mathrm{~m}$ in height), is divided into two parts by a metal plate placed vertically. The heating was achieved by superheated steam jacket as well as a mixture of superheated and saturated steam (Figure 1) from bottom to top. Since the experiments were made with a free autoclave volume, without any flow resistance, the steam rises vertically through the plate holes but with a preferentially horizontal direction from left to right with some projection against the wall on the right side, rising and moving then to the left.

Tests were performed at normal pressure and temperatures between $190^{\circ} \mathrm{C}$ and $210^{\circ} \mathrm{C}$ for 2,6 and 12 h. It was not possible to test the samples at lower temperatures since the minimum working temperature for the autoclave was $190^{\circ} \mathrm{C}$. The heating in the autoclave was done slowly up to $130^{\circ} \mathrm{C}$ through the sleeve and between $130^{\circ} \mathrm{C}$ and the working temperature the heating was quick and done with a mixture of saturated and superheated steam introduced inside the autoclave. The temperature of the treatment was maintained through the heating by the autoclave sleeve. The samples were taken from the autoclave after the treatment and placed in a desiccator. The mass loss was determined for each sample in relation to its initial dry mass as mentioned before.

For FTIR analysis, samples with approximately the same mass loss were chosen for both species and treatments. For each treatment, at least three samples were chosen, one with mass loss less than $1 \%$, another one with mass loss around 3\% which is generally considered the necessary mass loss to obtain a good stability, and a higher mass loss. For eucalypt treated in the autoclave a sample with mass loss less than $1 \%$ could not be obtained because all of the samples had a higher mass loss due to the treatment.

\section{FTIR Analysis}

Treated and untreated samples were cut into small pieces and then ground separately in a knife mill Retsch SMI, followed by a Thomas mill. The crushed material was subject to a screening using a Retsch AS200basic with 40, 60 and 80 mesh sieves. The sieving was carried out during a period of 20 minutes at a speed of $50 \mathrm{rpm}$. The sample was separated into 4 fractions ( $>40,40-60,60-80$ and $<80 \mathrm{mesh})$. The samples from the 40-60 fraction were then extracted with dichloromethane, ethanol and water and air 
dried, according to Tappi Standard (T $264 \mathrm{om}-88$ ). After that $200 \mathrm{mg}$ of air-dried wood were weighted, placed in an oven at $60^{\circ} \mathrm{C}$ overnight. The next day the samples were ground in a ball mill (Mixer Mill MM2, Retsch) for 30 min at maximum power and left in a desiccator over phosphorus pentoxide. Heat treated pine and eucalypt wood samples with similar mass losses were chosen to collect the spectra. One spectrum was collected for each treatment-time-species combination.

The spectra were obtained with 1.50 to $1.55 \mathrm{mg}$ of material with $200 \mathrm{mg}$ of dry $\mathrm{KBr}$ ground in a ball mill (Mixer Mill MM2, Retsch) for $20 \mathrm{~s}$. Disk (13 mm in diameter) were formed on a 10 tons load hydraulic press. The sample and reference spectra were obtained with 32 scans in a Bio-Rad FTS spectrometer 165 with a DTGS detector at $4 \mathrm{~cm}^{-1}$ resolution for the $500-4000 \mathrm{~cm}^{-1}$ range. As reference we used the empty sample compartment. The spectra were analysed with the program OPUS (Bruker), fixing the baseline on 20 points. No normalization was made since no band stayed unaltered throughout the treatment. To clarify some results the band height ratio between 1740 and $1650 \mathrm{~cm}^{-1}$ was determined according to Faix and Böttcher (1992).

\section{RESULTS AND DISCUSSION}

Figures 2 and 3 present the FTIR spectra of pine and eucalypt wood without treatment and after heat treatment in the oven. Eucalypt wood treated at $170^{\circ} \mathrm{C}$ for $2,6,12$, and $24 \mathrm{~h}$ had mass losses of $0.1 \%$, $1.1 \%, 2.7 \%$ and $3.7 \%$, respectively. While pine wood treated at $180^{\circ} \mathrm{C}$ during $2,6,12$, and $24 \mathrm{~h}$ had mass losses of $0.8 \%, 1.4 \%, 4.0 \%$ and $7.4 \%$, respectively.

Figures 4 and 5 present the FTIR spectra of pine and eucalypt wood without treatment and after treatment in autoclave. Eucalypt wood treated at $190^{\circ} \mathrm{C}$ during 2 and $12 \mathrm{~h}$ had mass losses of $4.8 \%$ and $9.0 \%$ respectively. While pine wood treated at $190^{\circ} \mathrm{C}$ during 2 and $6 \mathrm{~h}$ and at $210^{\circ} \mathrm{C}$ during $12 \mathrm{~h}$ had mass losses of $0.4 \%, 3.5 \%$ and $13.2 \%$ respectively. In order to show more than one spectrum in each figure a shifting in the y axis was made.

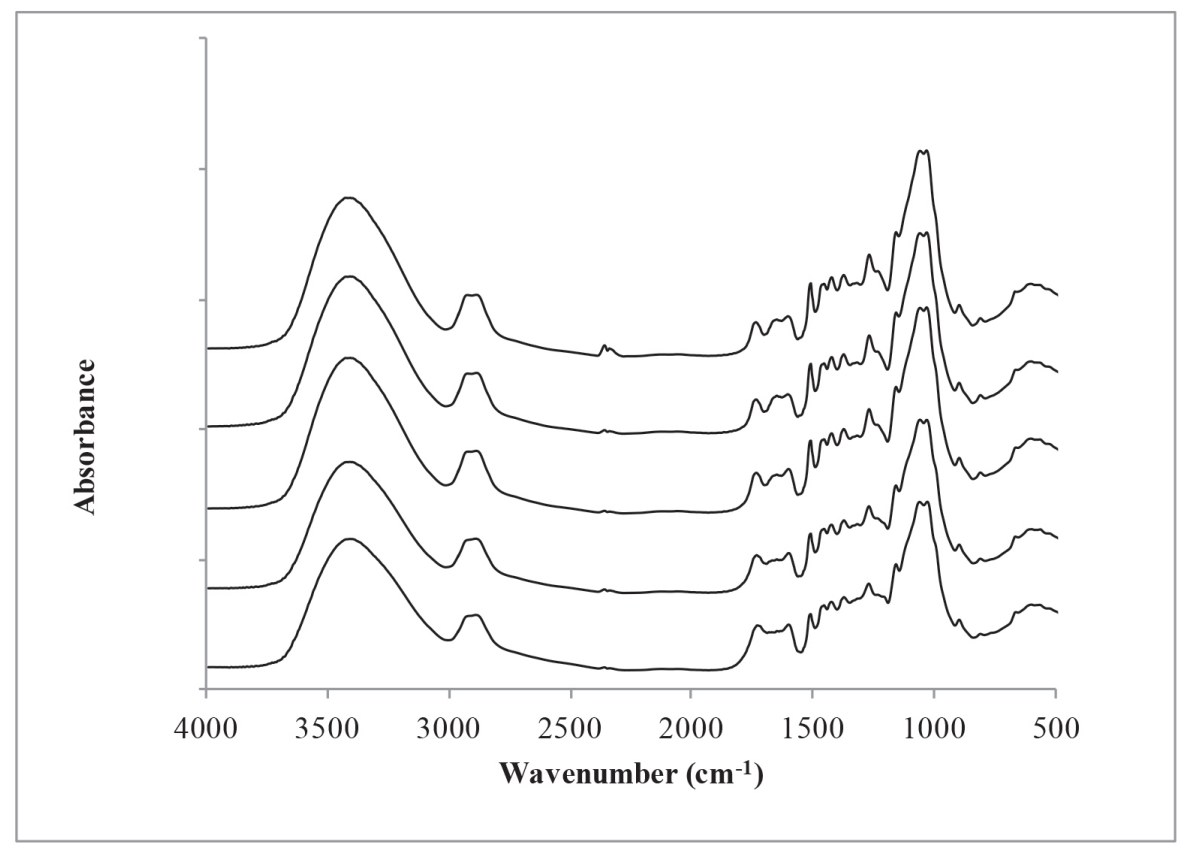

Figure 2. FTIR spectra of pine wood: from top to bottom without treatment initial and after treatment in an oven at $180^{\circ} \mathrm{C}$ for $2,6,12$ and $24 \mathrm{~h}$ 


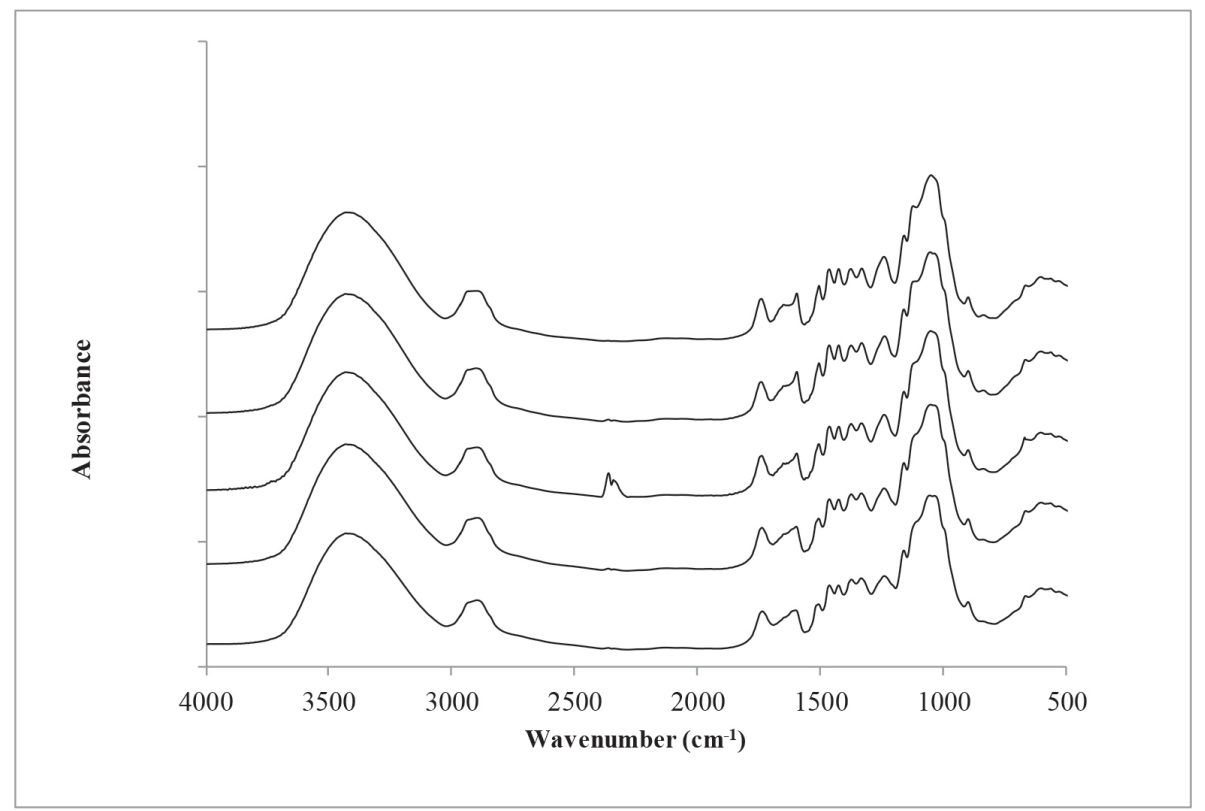

Figure 3. FTIR spectra of eucalypt wood: from top to bottom without treatment initial and after treatment in oven at $170^{\circ} \mathrm{C}$ for $2,6,12$ and $24 \mathrm{~h}$

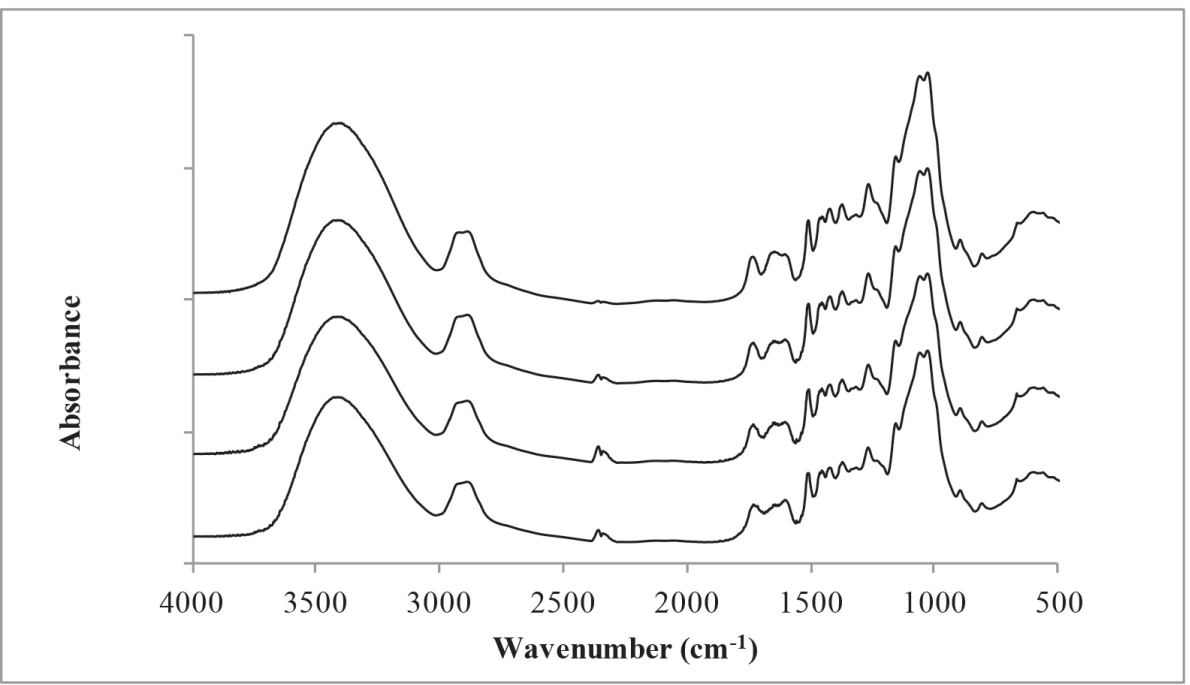

Figure 4. FTIR spectra of pine wood: from top to bottom without treatment initial and after treatment in autoclave at $190^{\circ} \mathrm{C}$ for $2,6 \mathrm{~h}$, and at $210^{\circ} \mathrm{C}$ for $12 \mathrm{~h}$ 


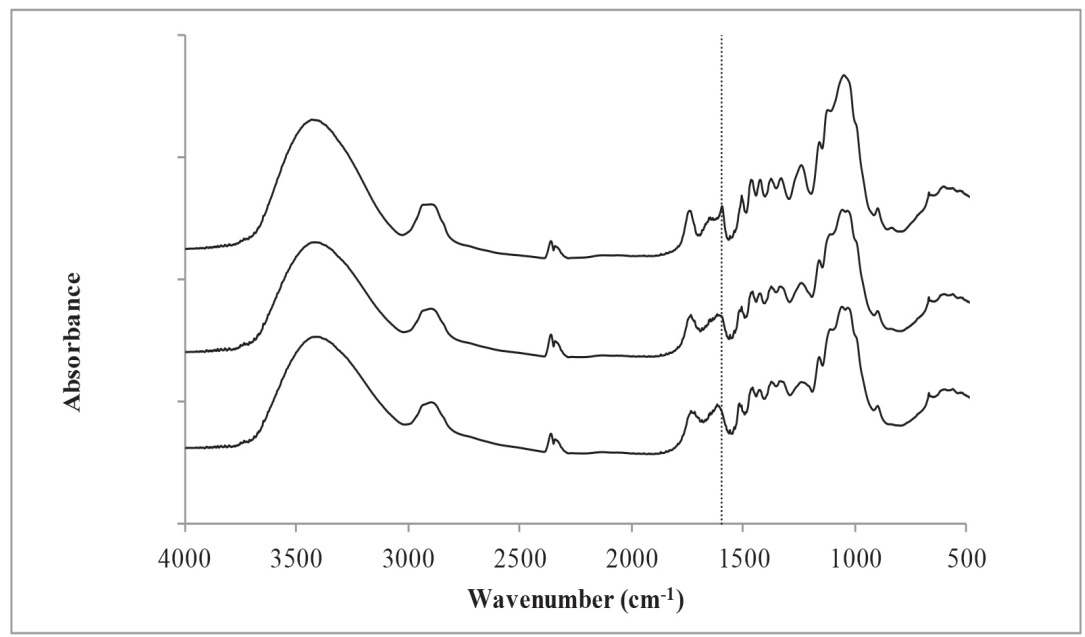

Figure 5. FTIR spectra of eucalyptus wood: from top to bottom without treatment initial and after treatment in autoclave at $190^{\circ} \mathrm{C}$ for 2 and $12 \mathrm{~h}$

Table 1 presents the most important bands that are observed in an infrared spectrum of wood and their assignment to functionality.

Table 1. Main bands of infrared spectrum of wood and their assignment to functionality

\begin{tabular}{|c|c|c|}
\hline $\begin{array}{l}\text { Wavenumber } \\
\left(\mathrm{cm}^{-1}\right)\end{array}$ & Functionality & Vibrating type \\
\hline 3400 & $\mathrm{O}-\mathrm{H}$ of alcohols, phenols and acids & O-H stretching ${ }^{1,2}$ \\
\hline $2970-2850$ & $\mathrm{CH}_{2}, \mathrm{CH}-$ and $\mathrm{CH}_{3}$ & C-H stretching ${ }^{1,2}$ \\
\hline $1750-1720$ & $\begin{array}{l}\mathrm{C}=\mathrm{O} \text { of esters, ketones, aldehydes } \\
\text { and acids }\end{array}$ & $\begin{array}{l}\mathrm{C}=\mathrm{O} \text { stretching, non- } \\
\text { conjugated }^{1,2}\end{array}$ \\
\hline $1700-1550$ & Conjugated $\mathrm{C}=\mathrm{O}$ and $\mathrm{C}=\mathrm{C}$ & $\begin{array}{l}\text { Conjugated } \mathrm{C}=\mathrm{O} \text { stretching, } \\
\text { and } \mathrm{C}=\mathrm{C} \text { stretching }\end{array}$ \\
\hline 1600 & Aromatic ring & $\begin{array}{l}\text { Benzene ring stretching } \\
\text { vibrations }\end{array}$ \\
\hline $1515-1500$ & Aromatic ring & $\begin{array}{l}\text { Benzene ring stretching } \\
\text { vibrations }\end{array}$ \\
\hline 1460 & $\mathrm{CH}$ & C-H deformations ${ }^{2}$ \\
\hline 1420 & Aromatic ring and $\mathrm{CH}$ & $\begin{array}{l}\text { Benzene skeletal combined } \\
\text { with C-H deformations }{ }^{1,2}\end{array}$ \\
\hline $1240-1330$ & Lignin $\mathrm{S}$ and $\mathrm{G}$ units and $\mathrm{OH}$ & $\begin{array}{l}\mathrm{C}-\mathrm{O} \text { stretching and bending } \\
\mathrm{OH}^{1,2} \\
\text { antisymmetric stretching } \\
\text { vibration of the acetyl ester } \\
\text { groups }\end{array}$ \\
\hline 1140 & G- Guaiacyl lignin and C-O & $\begin{array}{l}\mathrm{C}-\mathrm{H} \text { deformations in } \mathrm{G} \text { lignin } \\
\text { and } \mathrm{C}-\mathrm{O} \text { stretching }\end{array}$ \\
\hline 1128 & S- Syringyl lignin and C-O & $\begin{array}{l}\text { C-H deformations in } \mathrm{S} \text { lignin } \\
\text { and } \mathrm{C}-\mathrm{O} \text { stretching }{ }^{1,3}\end{array}$ \\
\hline $1025-1035$ & $\mathrm{C}-\mathrm{O}-\mathrm{C}$ & Deformation $^{1,2}$ \\
\hline 897 & $\begin{array}{l}\text { anti-symmetric out-of-phase } \\
\text { stretching in pyranose ring }\end{array}$ & stretching in pyranose ring 1,2 \\
\hline
\end{tabular}

${ }^{1}$ Rodrigues et al. (1998), ${ }^{2}$ Mitchell and Higgins (2002), ${ }^{3}$ Faix (1991) 
The differences between spectra from untreated and heat treated wood were difficult to interpret since there are several reactions occurring at the same time. Nevertheless, there were changes in the FTIR spectra of wood with the heating treatments even for the mildest conditions corresponding to small mass losses, as can be seen in the spectrum of eucalypt treated in oven (Figure 3 ) at $170^{\circ} \mathrm{C}$ during $2 \mathrm{~h}$, corresponding to $0.1 \%$ mass loss. Even thought there are not significant changes from untreated wood a small decrease of the $1740 \mathrm{~cm}-1$ peak was noticeable. With an increase in mass loss all of the wood compounds were affected leading to several changes in the spectrum.

It is a well known fact that chemical changes due to heat treatment start by deacetylation followed by depolymerization catalysed by the released acetic acid (Tjeerdsma et al 1998, Sivonen et al. 2002, Nuopponen et al. 2004). At the same time there is a carbohydrate dehydratation that reduces accessible $\mathrm{OH}$ groups (Weiland and Guyonnet 2003) and leading to the formation of furfural and hydroxymethylfurfural (Tjeerdsma and Militz 2005). Lignin bonds are cleaved, resulting in a higher concentration of phenolic groups (Kollmann and Fengel 1965). The increased reactivity leads to lignin autocondensation and condensation reactions with aldehydes.

The FTIR spectra of heat-treated pine and eucalypt wood (Figures 2-5) showed a broadening to lower wavenumbers of the band at $3430 \mathrm{~cm}^{-1}$ corresponding to the $\mathrm{O}-\mathrm{H}$ stretching vibration from alcohols (3600-3300 $\left.\mathrm{cm}^{-1}\right)$ and carboxylic acids $\left(3300-2500 \mathrm{~cm}^{-1}\right)$, present either in polysaccharides and lignin. We suggest that this broadening might be due to the increase in carboxylic acids due to primary $\mathrm{OH}$ oxidation and/or hydrolysis of acetyl groups from hemicelluloses. Moreover the change of O-H stretching frequencies can also be due to the modification of cellulose crystallinity influenced by dehydration effects (Moharram and Mahmoud 2008, Spiridon et al. 2011). Even though O-H stretch due to polysaccharides should decrease, at the same time $\mathrm{O}-\mathrm{H}$ from phenolic groups in lignin increases since it is a well known fact that the lignin percentage increases due to carbohydrate degradation (Esteves et al. 2011).

The two bands at 2900-2800 $\mathrm{cm}^{-1}$ are composed by the overlapping of the stretch asymmetric vibrations of $-\mathrm{CH}_{2}-\left(\right.$ generally around $\left.2935-2915 \mathrm{~cm}^{-1}\right)$ and $-\mathrm{CH}_{3}\left(2970-2950 \mathrm{~cm}^{-1}\right)$ and by the overlapping of stretch symmetric vibrations of $-\mathrm{CH}_{2}-\left(2865-2845 \mathrm{~cm}^{-1}\right)$ and $-\mathrm{CH}_{3}\left(2880-2860 \mathrm{~cm}^{-1}\right)$. Normally the asymmetric band presents a higher absorptivity. The apparent shift in frequency for the maximum of $\mathrm{CH}$ band is due to structural and relative composition changes, namely changes at cellulose crystallinity level which influences the C-H and O-H stretch frequencies (Moharram and Mahmoud 2008, Spiridon et al. 2011), and changes in the relative importance of lignin methoxyl groups for which the $\mathrm{CH}_{3}$ stretching vibrations have lower $\mathrm{CH}$ stretching frequencies (Coates 2000). If the $\mathrm{OCH}_{3}$ increases by reduction of the carbohydrates this implies that the contribution of the $\mathrm{OCH}_{3}$ becomes larger and the consequence is that we can see that the right shoulder becomes maximum. Although the asymmetric/symmetric stretch of methylene group $\left(-\mathrm{CH}_{2}-\right)$ appears at slightly lower wavelengths this does not necessary mean that there is an increase in methylene groups at the expense of methyl groups.

The $\mathrm{C}=\mathrm{O}$ linkage exhibits strong absorptions in FTIR spectra between 1750 and $1700 \mathrm{~cm}^{-1}$, and the precise wavenumber depends of the functional group (carboxylic acid: at about $1725-1700 \mathrm{~cm}^{-1}$; ester, ketone: $1725-1705 \mathrm{~cm}^{-1}$, aldehyde: $1740-1720 \mathrm{~cm}^{-1}$ ) and of its structural location, with lower wavenumbers for conjugated $\mathrm{C}=\mathrm{O}$. According to Mitchell and Higgins (2002), the band around $1730 \mathrm{~cm}^{-1}$ is almost exclusively due to the carbonyl groups of acetoxy groups in xylan. In the spectra of eucalypt and pine oven treated wood (Figures 2 and 3) this band decreased initially but for longer treatments the band increased, shifting to smaller wavenumbers. The decrease at the beginning of the heat treatment (with mass losses around 1\%) might be due to the breaking of acetyl or acetoxy groups in xylan. Similar results were obtained by Tjeersdsma and Militz (2005) after the first hydrothermal step of the Plato process and by Kocaefe et al. (2008b) with wood treated by the Perdure process. In the spectra of wood treated in autoclave (Figures 4 and 5) there was no initial decrease but only an increase and shifting to about $1730 \mathrm{~cm}^{-1}$. A possible reason for the absence of the initial decrease in these spectra is that the smaller mass losses for autoclave heat treated wood are around $4-5 \%$ and the cleavage of acetyl groups had 
already occurred, possible around 1-2\% mass loss. At these mass losses (4-5\%) the decrease can no longer be seen because another effect superimposes. The increase and shifting for smaller wavenumbers with increasing treatment severity may be due to an increase of carbonyl or carboxyl groups in lignin or carbohydrates by oxidation. This increase was also obtained by Kotilainen et al. (2000) with Pinus sylvestris and Picea abies and González-Peña et al. (2009) who attributed this increase to lignin condensation reactions at the expense of $\mathrm{C}=\mathrm{C}$ double bonds in conjugated carbonyl groups in lignin, vibrating at $1654 \mathrm{~cm}^{-1}$. Tjeerdsma and Militz (2005), who studied the FTIR spectra of holocellulose and lignin of heat-treated Fagus sylvatica and Pinus sylvestris, concluded that the increase of the $1740 \mathrm{~cm}^{-1}$ band was due only to the lignin as there was no increase in holocellulose. These authors considered this increase to be due to the occurrence of estherification when the existent acid reacts with the hydroxyl groups of the cell-wall material. If estherification occurs the band at $1240 \mathrm{~cm}^{-1}$ should also increase due to antisymmetric stretching vibration of the acetyl ester groups which with our samples does not happen. Nevertheless since this is a composed band the eventual increase could be overlapped by the decrease of other compound. Li et al. (2002) studied the heat degradation of lignin in hardwood and softwood and obtained an increase in the peak at $1720 \mathrm{~cm}^{-1}$ with increasing temperature, which they concluded to be due to the production of $\mathrm{C}=\mathrm{O}$ bonds in lignin.

To better understand what happens between 1800 and $1600 \mathrm{~cm}^{-1}$ wavenumber Figure 6 shows this range of figure 2 in detail (pine oven treated wood) and presents also the ratio of the band heights at 1740 and $1650 \mathrm{~cm}^{-1}$. In this figure an initial decrease followed by an increase of the $1740 \mathrm{~cm}^{-1}$ band in relation to $1650 \mathrm{~cm}^{-1}$ band can be seen. The maximum of the $1740 \mathrm{~cm}^{-1}$ band shifts from the initial point around $1738 \mathrm{~cm}^{-1}$ to about $1729 \mathrm{~cm}^{-1}$.

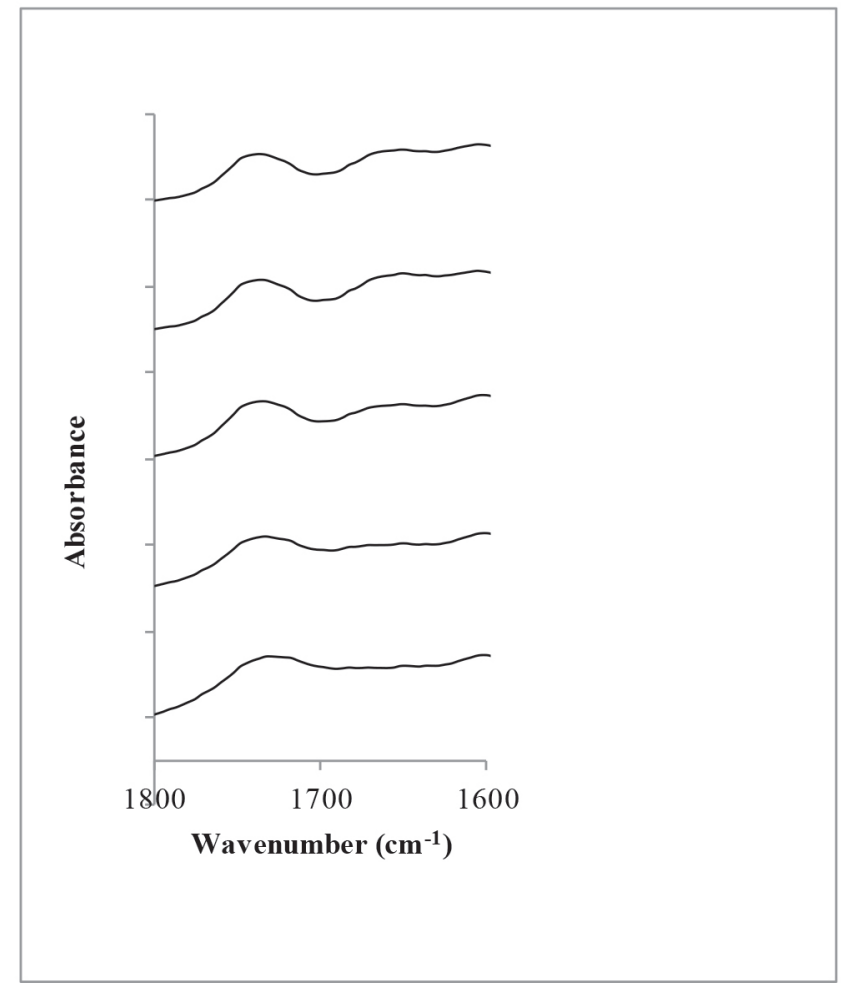

Figure 6. FTIR spectra of pine wood in the wavenumber range from 1800 to $1600 \mathrm{~cm}^{-1}$. From top to bottom: without treatment and after treatment in an oven at $170^{\circ} \mathrm{C}$ for $2,6,12$ and $24 \mathrm{~h}$ and ratio of band heights at $1740 \mathrm{~cm}^{-1} / 1650 \mathrm{~cm}^{-1}$. 
The increase of the peak at $1740 \mathrm{~cm}^{-1}$ in relation to $1650 \mathrm{~cm}^{-1}$ means that non-conjugated $\mathrm{C}=\mathrm{O}$ groups increased in relation to conjugated groups. Similar results were described by González-Peña et al. 2009.

The band at $1595 \mathrm{~cm}^{-1}$ corresponds to vibrations in the aromatic ring of lignin plus $\mathrm{C}=\mathrm{O}$ stretching. The band at $1595 \mathrm{~cm}^{-1}$ broadens to about $1613 \mathrm{~cm}^{-1}$ for eucalypt but not for pine wood (Figures 2 to 5). This peak broadening suggests that there was an increase of structural diversity around the aromatic rings, absorbing at a greater range of frequencies. The height of the band seemed to increase only in the spectrum of eucalypt wood treated in autoclave (Figure 5). According to Kotilainen et al. (2000) this band increases due to an increase in the percentage of lignin in treated wood. Li et al. (2002) also obtained an increase of the peak at $1595 \mathrm{~cm}^{-1}$ in lignin at temperatures between $25^{\circ} \mathrm{C}$ and $460^{\circ} \mathrm{C}$, although no explanation was given.

Aromatic rings exhibit, most of the times, a characteristic band at approximately $1500 \mathrm{~cm}^{-1}$, corresponding to benzene ring stretching vibrations. This band is very important because it is at about $1505 \mathrm{~cm}^{-1}$ for hardwood lignin (Guaiacyl - G and Syringyl - S) and at about $1510 \mathrm{~cm}^{-1}$ for softwood lignin (Guaiacyl-G) (Faix 1991). The band at $1505 \mathrm{~cm}^{-1}$ for eucalypt wood decreased, shifting to about $1512 \mathrm{~cm}^{-1}$ (Figure 7). This can be due to the decrease of the methoxyl groups in lignin which would lead to a lignin more similar to softwood (G-lignin) or to the loss of S units, since this monomer is generally less condensed by $\mathrm{C}-\mathrm{C}$ bonds than guaiacyl monomers and is more prone to be liberated by a thermal degradation (Faix et al. 1990).

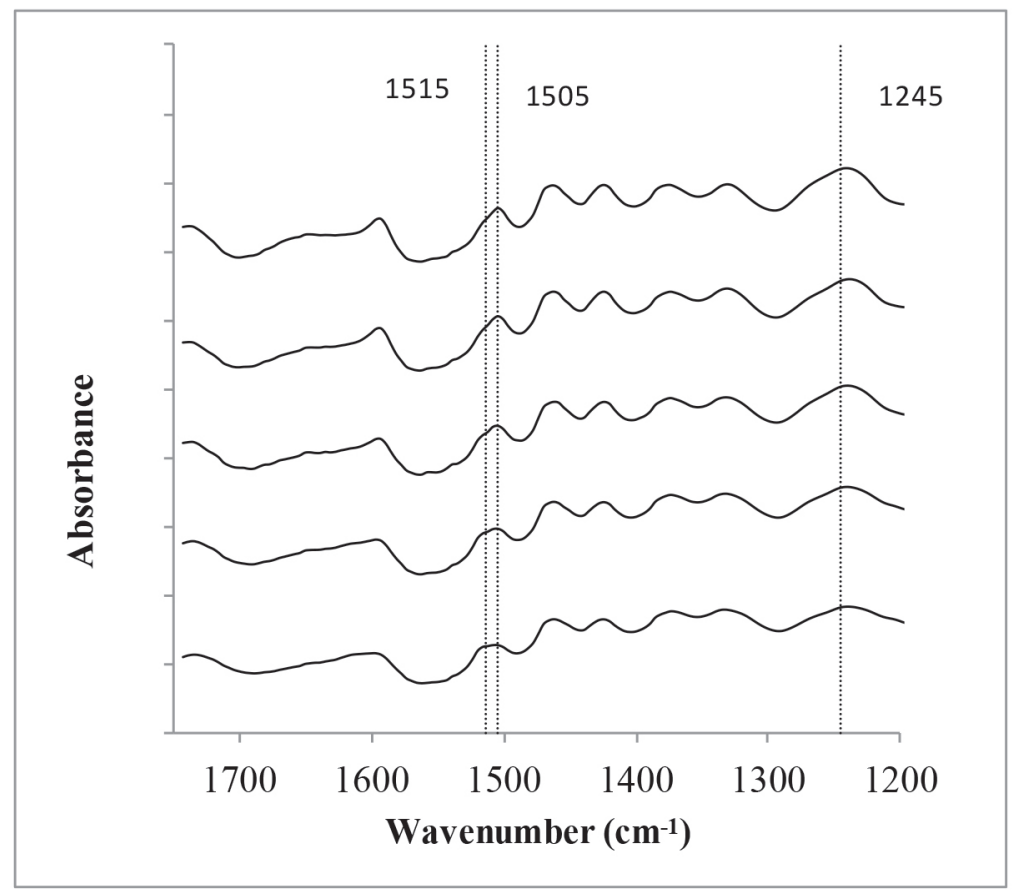

Figure 7. FTIR spectra of eucalypt wood from top to bottom without treatment and after treatment in oven at $170^{\circ} \mathrm{C}$ for $2,6,12$ and $24 \mathrm{~h}$ in the range $1750-1200 \mathrm{~cm}^{-1}$ 
The shifting of this band is in agreement to the results presented by Windeisen et al. (2007) and Kocaefe et al. (2008b), and attributed to the breaking of aliphatic side-chains in lignin and/or condensation reactions.

The band at $1460 \mathrm{~cm}^{-1}$ corresponds to the asymmetric deformation of $\mathrm{C}-\mathrm{H}$ bond of xylan, while the band at $1420 \mathrm{~cm}^{-1}$ corresponds to the vibration of the aromatic ring of lignin, but also to the $\mathrm{C}-\mathrm{H}$ bending in cellulose (Mitchell and Higgins 2002). No consistent variation was found for the $1460 \mathrm{~cm}^{-1}$ and $1420 \mathrm{~cm}^{-1}$ peak. According to Kotilainen et al. (2000) and Weiland and Guyonnet (2003) the peaks at $1460 \mathrm{~cm}^{-1}$ and $1420 \mathrm{~cm}^{-1}$ increase with heat treatment. The band at $1375 \mathrm{~cm}^{-1}$ broadened to smaller wavenumbers but with no consistent variance. The band at $1333 \mathrm{~cm}^{-1}$ represents the contributions of all structural components of wood because it corresponds to $\mathrm{C}-\mathrm{H}$ bending of polysaccharides which joins the band at $1327 \mathrm{~cm}^{-1}$ of S and G lignin condensed units (Faix 1991). There was a clear increase at $1330 \mathrm{~cm}^{-1}$ corresponding to an increase in lignin condensation. The same was reported by Windeisen et al. (2007).

For eucalypt wood (Figures 3, 5 and 7) the band at $1245 \mathrm{~cm}^{-1}$, decreased in height but broadened which once again confirms the existence of a more condensed structure (Windeisen et al. 2007, Kocaefe et al. 2008b). According to Kotilainen et al. (2000) this peak increases, but no explanation was given. The band at $1140 \mathrm{~cm}^{-1}$ is the result of the sum of the contribution of $\mathrm{C}-\mathrm{H}$ deformation in aromatic rings and $\mathrm{C}-\mathrm{O}$ stretching in primary alcohols. This band has a shoulder at $1140 \mathrm{~cm}^{-1}$ in woods with $\mathrm{G}$ lignin (Figure 2 and 4) and $1128 \mathrm{~cm}^{-1}$ in the woods with GS lignin (Figures 3 and 5) (Faix 1991). No consistent variation was found for this band.

The peak at $897 \mathrm{~cm}^{-1}$, corresponding to the sugar ring tension, seemed to decrease with increasing severity of the treatment which is consistent with ring opening (Figures 2 to 5). Similar results were obtained by Kotilainen et al. (2000) and González-Peña et al. (2009).

These results are generally consistent with the chemical changes determined by wet chemistry for heat treated pine and eucalypt in oven and in autoclave (Esteves et al. 2006, Esteves et al. 2008b, Esteves et al. 2011). In the beginning of the treatment, hemicelluloses are the first to degrade, as proved here by the initial decrease of the $1740 \mathrm{~cm}^{-1}$ peak attributed to the cleavage of acetyl or acetoxy groups in xylan. The attack on polysaccharides during heating is clear by the decrease of the peak at $897 \mathrm{~cm}^{-1}$ corresponding to the pyranose ring opening. The increase in lignin content that derived from the carbohydrate loss can be seen by the later increase of the $1740 \mathrm{~cm}^{-1}$ peak which according to Li et al. (2002) is due to the formation of carbonyl groups in lignin.

No significant differences between oven and autoclave treatments were observed. In the range of the studied thermal treatments and wood mass losses, no influence of air or steam heating was detected by FTIR analysis. The different chemical reactions occurring at the same time make the existing differences between spectra very difficult to follow. 


\section{CONCLUSIONS}

The heat treatment caused significant changes in the chemical composition and structure of wood, by changing polysaccharides and lignin. That can be observed by FTIR analysis. Hemicelluloses are the first components to degrade due to deacetylation. Hardwood lignin changes more than softwood lignin, due to demethoxylation, loss of S units or breaking of aliphatic side-chains. The macromolecular lignin structure becomes more condensed with the presence of non-conjugated/conjugated groups. The changes induced by the thermal treatment are due to different chemical reactions occurring simultaneously.

\section{ACKNOWLEDGEMENTS}

The authors thank the Portuguese Foundation for Science and Technology and the Centre for Studies in Education, Technologies and Health for the financial support.

\section{REFERENCES}

Bekhta, P.; Niemz, P. 2003. Effect of high temperature on the change in color, dimensional Stability and mechanical properties of spruce wood. Holzforschung 57(5): 539-546.

Coates, J. 2000. Interpretation of Infrared Spectra, A Practical Approach in Encyclopedia of Analytical Chemistry. R.A. Meyers (Ed.). John Wiley \& Sons Ltd. pp. 10815-10837

Dirol, D.; Guyonnet, R. 1993. Durability by rectification process. In: International Research Group Wood Pre, Section 4-Processes, N IRG/WP 93-40015.

Esteves, B.; 2006. Technological Improvement of Portuguese Woods by Heat Modification. Ph.D. Thesis in Environmental Engineering. School of Agronomy. Technical University of Lisbon. In Portuguese. 289p

Esteves, B.; Domingos, I.; Pereira, H. 2007a. Improvement of technological quality of eucalypt wood by heat treatment in air at $170-200^{\circ} \mathrm{C}$. Forest Prod $J 57$ (1-2): 47-52.

Esteves, B.; Velez Marques, A.; Domingos, I.; Pereira, H. 2007b. Influence of steam heating on the properties of pine (Pinus pinaster) and eucalypt (Eucalyptus globulus) wood. Wood Sci Technol 41(3):193-207.

Esteves, B. M.; Domingos, I. J.; Pereira, H. M. 2008a. Pine wood modification by heat treatment in air. Bioresources 3(1): 142-154.

Esteves, B.; Graça, J.; Pereira, H. 2008b. Extractive composition and summative chemical analysis of thermally treated eucalypt wood. Holzforschung 62(3):344-351.

Esteves, B.; Velez Marques, A.; Domingos, I.; Pereira, H. 2008c. Heat induced colour changes of pine (Pinus pinaster) and eucalypt (Eucalyptus globulus) wood. Wood Sci Technol 42(5): 369-384. 
Esteves, B.; Videira, R.; Pereira, H. 2011. Chemistry and ecotoxicity of heat treated pine wood extractives, Wood Sci Technol 45 (6 ):661-676.

Faix, O. 1991. Classification of lignins from different botanical origins by FT-IR spectroscopy. Holzforschung 45 (1): 21-27.

Faix, O. Böttcher, J. 1992. The influence of particle size and concentration in transmission and diffuse reflectance spectroscopy of wood. Holz als Roh- und Werkst 50(6): 221-226.

Faix, O.; Meier, D.; Fortmann, I. 1990. Thermal-degradation products of wood. Gas chromatographic separation and mass spectrometric characterization of monomeric lignin derived products. Holz als Rohund Werkst 48(7-8 ):281-285.

González-Peña, M.M.; Curling, S.F.; Hale, M.D.C. 2009. On the effect of heat on the chemical composition and dimensions of thermally-modified wood. Polymer Degradation and Stability 94(12): 2184-2193.

Jämsä, S.; Viitaniemi, P. 2001. Heat treatment of wood- Better durability without chemicals. In: Proceedings of special seminar held in Antibes, France, city, 68p.

Moharram, M.; Mahmoud, O. 2008. FTIR Spectroscopic Study of the Effect of Microwave Heating on the Transformation of Cellulose I into Cellulose II during Mercerization. Journal of Applied Polymer Science 107(1): 30-36.

Kamdem, D.; Pizzi, A.; Jermannaud, A. 2002. Durability of heat-treated wood. Holz Roh-Werkst 60(1): $1-6$.

Kocaefe, D.; Jun, L. S.; Yang, D.Q.; Bouazara, M. 2008a. Mechanical properties, dimensional stability, and mold resistance of heat-treated jack pine and aspen. Forest Prod J 58(6):88-93

Kocaefe, D.; Poncsak, S.; Boluk, Y. 2008b. Effect of thermal treatment on the chemical composition and mechanical properties of birch and aspen. Bioresources 3(2): 517-537.

Kollmann, F.; Fengel, D. 1965. Changes in the Chemical composition of Wood by Thermal Treatment. Holz als Roh und Werkst 12 (12): 461-468.

Kotilainen, R.; Toivannen, T.; Alén, R. 2000. FTIR monitoring of chemical changes in softwood during heating. Journal of Wood Chemistry and Technology 20(3): 307-320.

Li, J.; Li, B.; Zhang, X. 2002. Comparative studies of heat degradation between larch lignin and Manchurian ash lignin. Polymer Degradation and Stability 78: 279-285.

Michell, A.; Higgins, H. 2002. Infrared Spectroscopy in Australian Forest Products research. CSIRO Forestry and Forest Products, Melbourne, Australia 60p. 
Michell, A.; Watson A.; Higgins H. 1965. An infrared spectroscopic study of delignification of Eucalyptus regnans.. Tappi 48: 520-532.

Mitsui, K.; Takada, H., Sugiyama, M.; Hasegawa, R. 2001. Changes in the properties of lightirradiated wood with heat treatment: Part 1 Effect of treatment conditions on the change in color. Holzforschung 55(6): 601-605.

Nuopponen, M.; Vuorinen, T.; Jamsä, S.; Viitaniemi, P. 2004. Thermal modifications in softwood studied by FT-IR and UV resonance Raman spectroscopies. J Wood Chem Technol 24(1): 13-26.

Rodrigues, J.; Faix O.; Pereira H. 1998. Determination of lignin content of Eucalyptus globulus wood using FTIR spectroscopy. Holzforschung 52(1): 46-50.

Sailer, M.; Rapp, A.; Leithoff, H. 2000. Improved resistance of Scots pine and spruce by application of an oil-heat treatment. In: International Research Group Wood Pre, Section 4-Processes, $\mathrm{N}^{\circ}$ IRG/WP 00-40162.

Spiridon, I.; Teacă, C.; Bodîrlău, R. 2011. Structural changes evidenced by FTIR spectroscopy in cellulosic materials after pre-treatment with ionic liquid and enzymatic hydrolysis. Bioresources $6(1): 400-413$.

Sivonen, H.; Maunu, S.; Sundholm, F.; Jämsä, S.; Viitaniemi, P. 2002. Magnetic resonance studies of thermally modified wood. Holzforschung 56(6): 648-654.

TAPPI Test Method. 1988. Preparation of Wood for Chemical Analysis. T264 om-88. In Tappi Test Methods. Atlanta, GA: Technical Association of the Pulp and Paper Industry.

Tjeerdsma, B.; Boonstra, M.; Pizzi, A.; Tekely, P.; Militz, H. 1998. Characterisation of thermaly modified wood: Molecular reasons for wood performance improvement. Holz Roh-Werkst 56(3): 149-153.

Tjeerdsma, B.; Militz, H. 2005. Chemical changes in hydrothermal treated wood: FTIR analysis of combined hydrothermal and dry heat-treated wood. Holz als Roh- und Werkst 63(2): 102-111.

Unsal, O.; Ayrilmis, N. 2005. Variations in compression strength and surface roughness of heattreated Turkish river red gum, $J$ Wood Sci 51(4): 405-409.

Viitanen, H.; Jämsä, S., Paajanen, L.; Nurmi, A.; Viitaniemi, P. 1994. The effect of heat treatment on the properties of spruce. IRG/WP 94-40032, 4p

Viitaniemi, P.; Jämsä, S.; Viitanen, H.; 1997. Method for improving biodegradation resistance and dimensional stability of cellulosic products. United States Patent $\mathrm{N}^{\circ} 5678324$ (US005678324). http:// www.freepatentsonline.com/5678324.html 
Wang, J.; Cooper, P. 2005. Effect of oil type, temperature and time on moisture properties of hot oil-treated wood. Holz Roh-Werkst 63(6): 417-422

Weiland, J.; Guyonnet, R. 2003. Study of chemical modifications and fungi degradation of heatly modified wood using DRIFT spectroscopy. Holz als Roh und Werkst 61(3): 216-220.

Windeisen, E.; Strobel, C.; Wegener, G. 2007. Chemical changes during the production of thermotreated beech wood. Wood Sci Technol 41(6): 523-536.

Yildiz, S. 2002. Physical, mechanical, technological and chemical properties of beech and spruce wood treated by heating. PhD dissertation, Karadeniz Tech. Univ.; Trabzon, Turkey. 200p 